\title{
Engineering Mechanics Information Teaching Implementation in Spring Admission Classes
}

\author{
Yanxia Wang \\ School of Transportation and Vehicle Engineering, Shandong University of Technology, Zibo \\ 255049, china
}

wangyx200@163.com

\begin{abstract}
Keywords: Spring admission; Information technology; Engineering mechanics; Classroom teaching; Network teaching.
\end{abstract}

\begin{abstract}
Engineering mechanics is the first course which has practical engineering problem that the college students learn at college. There are too many concepts, theorems and formulas in this subject. Spring admission students mostly just received junior high school education or high school education, and they have low cultural quality and bad study habit. The goal of spring admissions is to cultivate engineering senior specialized talents with enterprising spirit and practical ability. So teachers should explore different ways, with their unremitting efforts, to treat spring admissions students. "Mixed Teaching Pattern" is the change and inheritance of college teaching under current information background. The mixed teaching pattern combines "teaching in classroom" with "teaching on internet". In this paper, combined with the students' characteristics from spring Admission and the characteristics of engineering mechanics a mixed teaching pattern of engineering mechanics is explored on content construction, execution plan and the intended effect.
\end{abstract}

\section{Introduction}

Spring admission enrols secondary vocational school graduates and ordinary high school graduates, but mainly specialized secondary school students. Those students mostly just received junior high school education or high school education. Their mathematics ability and intellectual ability for engineering mechanics learning are not good enough, especially the ability to analyse and solve problems. The goal of spring admissions is to cultivate engineering senior specialized talents with enterprising spirit and practical ability. The students from spring admission should have strong hands-on ability and, could use the theoretical knowledge to analyse and solve practical problems on the first production line [1-3].

Engineering mechanics is the first course which has practical engineering problem that the college students learn at college. There are too many concepts, theorems and formulas in this subject. The theory is abstract and lack of the connection with practical production. However, with the popularization of higher education the access to college becomes easier and students' intelligent level is quite different, especially those from spring admission; they have low cultural quality and bad study habit. It is a problem for teachers who are used to elite education. If considering the integrity of their subject system, it is bound to lead to focus on imparting theoretical knowledge, causing students' ability to analysis and solve problems insufficient. Aiming at this phenomenon, the author, according to years of teaching experience, comes up with the preliminary discussion on the "Engineering Mechanics Mixed Teaching Pattern" of spring admission students [4-9].

\section{Content of Mixed Teaching Pattern}

The mixed teaching pattern combines "teaching in classroom" with "teaching on internet". Classifying the knowledge points with theory and practice or teaching and self-learning, basing on the nature of the engineering mechanics course and the importance in the cultivation of professional ability [10-13]. To theory part, teaching knowledge in classroom is the main method; to practice part, Cultivating students' ability to gain knowledge is the main point with teaching on internet. The construction contents mainly include: 
Dividing Teaching Knowledge Scientifically. Teacher divides the teaching knowledge points based on the teaching content, objective requirements and key points. The teaching knowledge should be completed in classroom and the self-study knowledge should be completed by network teaching. The practical knowledge points should be completed by classroom experimental teaching and extracurricular network based science and technology innovation activities.

For example, we should divide the knowledge points into the intensity and rigidity in the course of "strength and rigidity of the beam under basic deformation". The detailed teaching contents include: the internal force and the internal force diagram of basic deformation, the stress distribution law and the calculation formula of the basic deformation; Hooke's law and the calculation of deformation; the strength and rigidity of the component should be completed by classroom theory teaching; mechanical properties of materials in tension and torsion, and bending normal stress test should be taught in classroom experiment teaching; improve the strength and rigidity of the component and the stress concentration phenomenon should be finished by "network teaching".

Combination of Classroom Theory Teaching and Experiment and Extracurricular Network Teaching. In the process of teaching, the main role of students should be stressed, and classroom theory teaching, classroom experimental teaching and extracurricular teaching should be combined into one various open teaching method. Students' cognitive ability and the characteristics of curriculum should be considered when students are guided to think actively, explore bravely, participate in communication and learn with enthusiasm; encouraging them to be brave to raise questions and take challenges; promoting them to actively learn in a creative way.

To combine theory teaching in classroom with experiment, theory will guide experiment, and experiment could verify theory. The understanding of theory could be strengthened by the experimental results. For example, through the bending test experiment, the simple beam bending stress distribution characteristics could be verified for the calculation formula of bending stress, so the formula will be understood and memorised deeply.

To combine the classroom teaching with extracurricular resources teaching through college innovative activities, the theory and experiment and practice will be combined closely. Students will learn the theoretical knowledge and at the same time the target of experiment, the purpose of practice all could be improved making up for the lack of time and mobilizing the enthusiasm of learning. As results students' learning and innovation ability will get improved. For example, students are divided into 6-8 groups to do a lecture in the classroom in the course of strength theory. Combining classroom teaching knowledge with online information, the mechanical cause of the wreck of the Titanic, the frost crack of automobile tanks in cold winter and the reason for boiling water removing fruit rind can be well explained.

Pay more Attention to the Process of Assessment and Assessment of Students' Mastery of the Knowledge of Engineering Mechanics and its Application. Students' Graduation assessment results from the usual assessment (including attendance, homework, classroom discussion), the period of performance (including the period of time in the test results, research papers and summary, innovative research results, etc.), flip the classroom results (arranged two flip classroom, the district average), the experimental results and the final exam results and other components.

\section{Implementation Plan of Mixed Teaching Pattern}

The mixed pattern of Engineering Mechanics mainly consists of three stages: basic knowledge stage, knowledge expanding stage and practical application stage. In different stage, teaching methods are not the same. Specific implementation is as follows:

Basic Knowledge Stage: Breaking the Key and Difficult Point through Intensively Teaching. Using mixed teaching mode can make full use of the advantage of big classroom, which is conducive to the arrangement of teaching content and the key points and difficult points of each lesson". For example, when the teacher is teaching "bending stress", the emphasis is on the distribution of normal stress in bending, the calculation formula and the strength conditions". By using Multi-Media the distribution law of normal stress is showed, and then some questions can be 
exported: 1) Are the strength calculation method of low carbon steel and cast iron the same? 2) How to calculate the asymmetric cross section when the cast iron materials have positive maximum bending moments and the negative one? Guiding and inspire students to analyse and discuss the above questions will help to deepen students' understanding of the key and difficult knowledge and strengthen their thinking ability.

Knowledge Expansion Stage: to carry out Autonomous Learning Based on Problem Oriented. According to the design of the mixed teaching mode, teachers need to teach the contents of the chapters to be sorted out, release the knowledge points in the form of problems in the school network teaching platform, and inspire students to think and learn according to the problem, in order to guide students to carry out autonomous learning. And then teachers redesign content of classroom teaching according to student learning tasks completed online case. For example: In the classroom, teachers and students together briefly review the online platform of learning tasks, through the online "teaching problem" of autonomous learning and discussion by students, to understand and evaluate the students to learn the content of the master when the teacher is teaching "the strength and rigidity of combined deformation". Through teaching animation, students' understanding and mastering of knowledge could be strengthened in learning, such as the superposition of internal force in combined deformation and the extraction of the unit body of the dangerous point. Using the hybrid teaching mode of "network + classroom", it is good for students' ability to analyse and solve problems.

Practical Application Stage: Task Driven Group to Assist Students to Carry out Autonomous Learning. Teachers in the classroom layout and curriculum content related research topics, students are required to set up a learning group, and taking full advantage of the engineering mechanics quality course network, School Engineering Mechanics network teaching platform, the library's electronic resources and library data and other resources to complete the project research. For example: According to the four kinds of basic deformation, the teacher asks the students to consult the relevant literature resources, to find out the basic deformation of the case from the real life, and to simplify the mechanical model, analysis of its internal force, stress and deformation after the completion of the study of the strength and rigidity of the pole pieces in the basic deformation. At the same time, the teacher asks the students to submit the survey report of "rod in the basic deformation strength, stiffness of progress", and make the appropriate PPT summary. This method provides a platform for students to display their learning achievements, and it also reflects the value of group cooperative learning in a certain sense. In the specific task of the driving, students through cooperation and competition, and stimulate their learning potential constantly, in practice to improve the interest and enthusiasm of active learning, effectively develop the habit of autonomous learning.

\section{Summary}

In the blended teaching process of Engineering Mechanics, teacher should change the teaching perspective from teaching traditional theory to developing students' learning ability, focusing on using knowledge to solve practical problem. Therefore, to achieve this goal it is necessary to continue accumulating teaching experience and improving the teaching organization of the course. It should stress students' subject position and teachers' guiding role in this teaching process and, advocate the use of multimedia teaching, problem teaching, discussion teaching, case teaching, network teaching, and flip the classroom and other open teaching methods. Rely on students' cognitive ability and the characteristics of the course, guide students to think actively, explore, participate in communication; stimulate students' enthusiasm in learning and encourage them to be brave and innovative to raise questions and meet the challenges. In terms of assessment, the combined model of process assessment and final assessment could comprehensively evaluate students' mastery of the knowledge and application ability of engineering mechanics. 


\section{Acknowledgements}

This work was financially supported by the excellent course in Shandong Province "Engineering Mechanics", a grant from National High Technology Research and Development Program of China (863 Program) (2009AA063202) and the Shandong Province Natural Science Fund (ZR2009FQ023, ZR2011EL017, ZR2013EEQ008).

\section{References}

[1] W.S. Liu, M.C. Fu, C.L. Zhang: Exploration of creative education in the teaching of engineering mechanics, Journal of Liaoning vocational college, 6 (2008) 23-24. (In Chinese)

[2] Y.X. Peng, J.G. Wang: Exploration and practice of the creative education in the teaching of engineering mechanics, Journal of education research, 4 (2007) 32-33. (In Chinese)

[3] Q.S. Fan: Engineering Mechanics (Higher Education Press, Beijing 2013). (In Chinese)

[4] Southwest Jiaotong University: Department of Applied Mechanics and Engineering. Engineering Mechanics Tutorial (Higher Education Press, Beijing 2013). (In Chinese)

[5] H.Z. Chan: Engineering mechanics (Higher Education Press, Beijing 2009). (In Chinese)

[6] H.W. Liu: Material Mechanics (Higher Education Press, Beijing 2011). (In Chinese)

[7] S.Q. Yu, Q.L. Lu and S.J. Chen: Mixed Teaching under the Network Environment---A new teaching mode, China University Teaching, 10 (2005) 50-56. (In Chinese)

[8] J.X. Xiong, B.F. Peng and H. Qi: Thinking of universities mixed teaching pattern under the background of informationization, Course education research, 5 (2012) 26-27. (In Chinese)

[9] Information on http:/www.enetedu.corn/course.

[10] J.Z. Zhang: Teachers' Information Technology Teaching Practice Ability Analysis, China Management Informationization, 12 (2015) 253-254. (In Chinese)

[11] Y. Zhan, Y.Q. Ren: Connotation Briefly of Subject Teaching Knowledge Integration Technology and Research Status, Remote Education, 4 (2010) 78-87. (In Chinese)

[12] J.L. Jiao, H.R. Zhong: Research issues and progress of tpack. Remote Education. 1 (2010) 3945. (In Chinese)

[13] Information on http:/www.enetedu.com/course. 